\title{
Prognostic Role of Red Distribution Width (RDW) Value in Gastric Cancer
}

\author{
Cemil Yüksel ${ }^{1}$, Ogün Erşen², Serdar Culcu, Batuhan Bakırarar ${ }^{3}$, Ali Ekrem Unal ${ }^{2}$ and Salim Demirci ${ }^{2}$ \\ ${ }^{1}$ Department of Surgical Oncology, University of Health Science, Ankara Abdurrahman Yurtaslan Oncology Training and Research \\ Hospital, Turkey \\ ${ }^{2}$ Department of Surgical Oncology, Ankara University School of Medicine, Turkey \\ ${ }^{3}$ Department of Biostatistics, Ankara University School of Medicine, Turkey
}

\begin{abstract}
Objective: To investigate the prognostic effect of red distribution width (RDW) in patients with gastric cancer.

Study Design: Observational study.

Place and Duration of Study: Department of Surgical Oncology, Ankara University School of Medicine, between November 2010 and January 2020.

Methodology: Patients diagnosed with adenocarcinoma by biopsy, who underwent radical surgery and lymph node dissection, and had preoperative RDW value, were inducted. Patients who had history of active inflammation in the past three months, received treatment for hematology disorder, blood transfusion, malignancy other than gastric cancer, autoimmune disease, venous thrombosis, or under 18 years of age, and those having cardiac and cerebrovascular diseases and distant metastases were excluded from the study. Apart from diagnosis, preoperative blood values, clinicopathologial, demographic features, and follow-up data were included in the study.

Results: RDW average value was $15.11 \pm 2.87$ and median value was $14.3 \%$. For RDW cut off value, $13.4 \%$ was accepted as reference from previous studies was divided into two groups as $<13.4 \%$ and $\geq 13.4 \%$. While it was $<13.4 \%$ in 119 patients; in 292 patients, it was " $\geq 13.4 \% "$. High RDW value showed poor survival $(p<0.001)$.

Conclusion: RDW, the current hematological marker, can be used as an important indicator for monitoring the progression and prognosis of gastric cancer.
\end{abstract}

Key Words: Gastrectomy, Gastric cancer, Laparoscopy, Surgical oncology, Red distribution width, survival.

How to cite this article: Yüksel C, Erşen O, Culcu S, Bakırarar B, Unal AE, Demirci S. Prognostic Role of Red Distribution Width (RDW) Value in Gastric Cancer. J Coll Physicians Surg Pak 2021; 31(01):21-26.

\section{INTRODUCTION}

Gastric cancer is still one of the most common cancers in the world and is one of the leading causes of cancer-related death. ${ }^{1}$ Most patients are diagnosed at an advanced stage and there is usually distant metastasis at the time of diagnosis. The average 5-year survival of these patients is around $10 \%$. Improvement in survival is observed due to improvement in diagnosis and treatment. Genetic and environmental factors are important fisk factors in the development of gastric cancer. In addition, inflammation has also been shown to play a role in gastric cancer development. When it comes to inflammation, factors such as cytokines, chronic irritation, infection, chemokines and epithelial dysfunction play a role.

Correspondence to: Dr. Cemil Yüksel, Department of Surgical Oncology, University of Health Science, Ankara Abdurrahman Yurtaslan Oncology Training and Research Hospital, Turkey

E-mail:cemil8537@hotmail.com

Received: October 02, 2020; Revised: December 11, 2020; Accepted: December 22, 2020

DOI: https://doi.org/10.29271/jcpsp.2021.01.21
Although some of the most important prognostic factors in gastric cancer are tumor stage and node status; in the early stages, there may be patients with poor prognostic features. So, more parameters are needed for prognosis. Hematological and biochemical parameters, which allow the prediction of prognosis in cancer patients, have attracted attention in recent years. Some of these are neutrophilic / lymphocyte ratio (NLR), CRP level, C-reactive protein (CRP)-Albumin (Alb) ratio, albumin and globulin levels and RDW.

RDW is one of the routine laboratory parameters along the complete blood count test, which shows the variability in the size of circulating red blood cells. ${ }^{2}$ The size of the red blood cells is 6-8 micro meters in normal blood values, and their sizes vary incase of inflammation and cancer. The increase in RDW had been previously associated with anemia (B12 deficiency, iron deficiency anemia), ${ }^{3}$ and has been shown to be associated with inflammation, nutritional status, many types of cancer (gastrointestinal tract, lung, breast, liver), and cardiovascular diseases in subsequent publications. ${ }^{4}$ The high RDW value has been shown to have prognostic significance in many types of cancer. ${ }^{5}$ It has also been shown that high RDW causes an increase in hospital mortality in somestudies. ${ }^{6}$ 
The aim of this study was to investigate the prognostic effect of RDW in patients with gastric cancer.

\section{METHODOLOGY}

Data of 411 patients, who underwent gastrectomy for gastric cancer between November 2010 and January 2020 in Department of Surgical Oncology Ankara University School of Medicine, were retrospectively analysed. All patients underwent open/laparoscopic, subtotal or total gastrectomy and lymph node dissection. The inclusion criteria of the study were patients who were diagnosed with adenocarcinoma by biopsy and underwent radical surgery and had preoperative RDW value.

Patients who had history of active inflammation in the past three months, received treatment for hematology disorder, had blood transfusion or malignancy other than gastric cancer or autoimmune disease or venous thrombosis; under 18 years of age, had cardiac and cerebrovascular diseases and distant metastases, were excluded from the study. This study was approved by the Ethical Committee of Ankara University School of Medicine.

Apart from diagnosis, preoperative blood values, clinicopathological demographic features, and follow-up data were evaluated for the study. TNM stage was assessed according to the $8^{\text {th }}$ edition, American Joint Committee on Cancer TNM staging. Follow-up was performed every three months for the first two years, every six months for the next three years and every year for five years after surgery. Workup included hematological and biochemical tests, tumor markers, thoracoabdominopelvic computed tomography (CT) or magnetic resonance imaging (MRI) and endoscopy. CT / MRI was performed every six months in the first two years, and every 12 months after two years and, endoscopy was performed once a year. RDW results were obtained by using an automatic hematological analyser within one hour after puncture from the vein in the hospital (Beckman Coulter LH 750; USA). The reference range of RDW in the hospital laboratory is 10 to $14 \%$. RDW cut-off value was divided into two groups as $<13.4 \%$, and $\geq 13.4 \%$ based on the previous studies. ${ }^{7,8}$

SPSS 25.0 programme was used in the analysis of the data. As descriptive, mean \pm standard deviation and median $\left(25^{\text {th }}\right.$ percentile- $75^{\text {th }}$ percentile) for quantitative variables and number of patients (percent) for qualitative variables were used. In the examination of a statistically significant difference between the categories of a qualitative variable with two categories in terms of a quantitative variable, the Mann Whitney Utest was used if the normal distribution assumption was not met. In the examination of a statistically significant difference between the categories of a qualitative variable with more than two categories in terms of a quantitative variable, the Kruskal Wallis $\mathrm{H}$ test used if the normal distribution assumption was not met. The relationship between two quantitative variables was analysed using the Spearmen correlation coefficient if the normal distributionassumption was notmet. Kaplan-Meieranal- ysis was used for calculating the overall survival and the logrank test to compare the survival rate curves. Statistical significance level was taken as $p<0.05$.

\section{RESULTS}

All the 411 patients underwent gastrectomy for gastric cancer. Two hundred and sixty-one (63.5\%) patients were males and $150(36.5 \%)$ were females. The mean and median values of the patients' age were found to be $61.50 \pm 12.98$ and 62 years (54.00-71.00), respectively. Patients were divided into two groups as age groups $\leq 60$ and $>60$. One hundred and eighty-five $(45.0 \%)$ of the patients were $\leq 60$, while 226 (54.9\%) of them were $>60$ years. A statistically significant borderline relationship was found between the two groups in terms of survival $(p=0.050)$. The tumor was located in the cardia in 117 patients, in the corpus in 88 and in the antrum in 206. There was no significant correlation between survival, according to tumor localisation $(p=0.976)$. The average survival time of the patients is 28.03 (10.00-42.00) months and 205 of these patients survive.

One hundred and thirty-one (31.9\%) patients had total open, $134(32.6 \%)$ had subtotal $103(25.1 \%)$ had laparoscopic subtotal, and 43 (10.5\%) had laparoscopic total gastrectomy. The relationship between type of surgical procedure and survival was statistically significant $(p=0.004)$. The worst survival was found in laparoscopic total gastrectomy (38.95 months), while the best survival was seen in laparoscopic subtotal gastrectomy (47.41 months). Sixty- four (15.6\%) of them were $T_{1}, 43$ (10.5\%) of them were $T_{2}, 130$ (31.6\%) of them were $T_{3}, 174(42.3 \%)$ of them were $T_{4}$. There was statistically significant difference between the groups in terms of survival $(p<0.001)$. Likewise, 148 of the patients were node negative while 263 of them were node positive. Survival was statistically significantly higher in patients with negative node $(p<0.001)$. According to stage grouping IA, IB, IIA, IIB, IIIA, IIIB, IIIC were 57, $36,55,45,58,71$ and 89 patients, respectively, with a statistically significant relationship between the stage and survival ( $p$ $<0.001$, Figure 1 ).

RDW average value was $15.11 \pm 2.87$ and median value was $14.3 \%$. For RDW cut-off value, $13.4 \%$ was accepted as reference from previous studies and it was divided into two groups as $<13.4 \%$ and $\geq 13.4 \%$. While it was $<13.4 \%$ in 119 patients; it was $\geq 13.4 \%$ in 292 patients. High RDW value shows poor survival $(p<0.001$, Table l). Albumin value was examined in two categories. There were 173 patients with $\leq 3.5 \mathrm{~g} / \mathrm{dl}$ and 238 patients with $>3.5 \mathrm{~g} / \mathrm{dl}$. It was found statistically significant that hypoalbuminemia shows poorsurvival $(p<0.001$, Figure 2$)$

Astatistically significant relationship was found between operation type and RDW. RDW value (14.60) was found to be the highest in patients who underwent open subtotal gastrectomy, while the RDW value was lowest in patients who underwent laparoscopic total gastrectomy $(14.00)(p=0.001)$. A statistically significant difference was found between laparoscopic subtotal-open total gastrectomy $(p=0.016)$ and laparoscopic subtotal-open subtotal gastrectomy $(p=0.002)$ in terms of RDW. 
Table I: Kaplan-Meier analysis results.

\begin{tabular}{|c|c|c|c|c|c|c|c|}
\hline \multirow[b]{3}{*}{ Variables } & & \multicolumn{5}{|c|}{ Survival } & \multirow[b]{3}{*}{ p-value } \\
\hline & & \multirow[b]{2}{*}{$\begin{array}{c}3 \text { years } \\
(\%)\end{array}$} & \multirow[b]{2}{*}{5 years $(\%)$} & \multirow[b]{2}{*}{$\begin{array}{c}9 \text { years } \\
(\%)\end{array}$} & \multicolumn{2}{|c|}{ Survival time } & \\
\hline & & & & & $\begin{array}{c}\text { Mean } \\
\text { (months, 95\% C.I) }\end{array}$ & $\begin{array}{c}\text { Median } \\
\text { (months, 95\% C.I) }\end{array}$ & \\
\hline Overall survival & & 88.8 & 65.7 & 25.9 & $54.30(48.62-59.98)$ & $33(25.78-40.22)$ & - \\
\hline Condor & Male & 48.9 & 41.7 & 31.3 & $54.82(47.78-61.86)$ & $35(24.61-45.39)$ & \multirow{2}{*}{0.640} \\
\hline हैना & Female & 46.4 & 38.8 & - & $51.91(44.06-59.76)$ & $31(21-41)$ & \\
\hline \multirow{3}{*}{ Location } & Cardia & 49.3 & 42.3 & 33.8 & $54.91(45.38-64.45$ & $35.00(15.26-54.75$ & \multirow{3}{*}{0.976} \\
\hline & Corpus & 49.4 & 38.8 & - & $44.33(36.45-52.21)$ & $35.00(19.34-50.66)$ & \\
\hline & Antrum & 46.5 & 40.3 & - & $46.66(41.30-52.02$ & $31.00(23.33-38.67)$ & \\
\hline \multirow{4}{*}{ Surgical procedure } & Open Total & 40.6 & 36.4 & 25.9 & $46.41(38.41-54.41)$ & $23.00(15.26-30.74)$ & \multirow{4}{*}{0.004} \\
\hline & Open Subtotal & 43.9 & 37.2 & - & $44.49(38.40-50.58)$ & $29.00(22.51-35.49)$ & \\
\hline & Lap. Total & 67.9 & - & - & $38.95(32.41-45.50)$ & - & \\
\hline & Lap. Subtotal & 62.1 & 58.2 & - & $47.41(40.93-53.88)$ & - & \\
\hline \multirow{4}{*}{ T stage } & 1 & 76.4 & 65.3 & - & $76.88(65.20-88.56)$ & - & \multirow{4}{*}{$<0.001$} \\
\hline & 2 & 64.2 & 51.4 & 51.4 & $69.53(52.67-86.40)$ & - & \\
\hline & 3 & 58.8 & 53.2 & - & $51.97(45.74-58.20)$ & - & \\
\hline & 4 & 28.4 & 22.3 & - & $34.08(28.60-39.56)$ & $20.00(16.51-23.50)$ & \\
\hline \multirow{2}{*}{ N stage } & Negative & 74.4 & 65.0 & 65.0 & $79.74(71.45-88.04)$ & - & \multirow{2}{*}{$<0.001$} \\
\hline & Positive & 34.5 & 28.3 & - & $39.27(34.37-44.18)$ & $22.00(17.99-26.01)$ & \\
\hline \multirow{7}{*}{ Stage } & $1 \mathrm{~A}$ & 81.2 & 68.1 & - & $80.30(68.15-92.44)$ & - & \multirow{7}{*}{$<0.001$} \\
\hline & $1 \mathrm{~B}$ & 75.6 & 64.8 & 64.8 & $79.89(62.22-97.56)$ & & \\
\hline & $2 \mathrm{~A}$ & 61.3 & 58.2 & - & $51.27(43.23-59.30)$ & - & \\
\hline & $2 B$ & 49.8 & 46.0 & - & $42.32(33.31-51.32)$ & $35.00(-)$ & \\
\hline & $3 \mathrm{~A}$ & 45.1 & 31.5 & - & $39.99(30.97-49.00)$ & $28.00(14.38-41.62)$ & \\
\hline & $3 \mathrm{~B}$ & 29.0 & 24.7 & - & $34.64(25.77-43.51)$ & $16.00(9.98-22.02)$ & \\
\hline & $3 C$ & 26.6 & 22.0 & - & $34.33(26.70-41.97)$ & $21.00(15.30-26.70)$ & \\
\hline \multirow{2}{*}{ RDW } & $<13.4$ & 78.4 & 74.7 & - & $83.71(76.01-91.42)$ & - & \multirow{2}{*}{$<0.001$} \\
\hline & $\geq 13.4$ & 36.7 & 28.4 & 14.2 & $41.20(34.77-47.62)$ & $22.00(17.73-26.27)$ & \\
\hline \multirow{2}{*}{ Albumin } & $\leq 3.5$ & 27.7 & 19.0 & - & $33.72(28.08-39.36)$ & $19.00(15.77-22.27)$ & \multirow{2}{*}{$<0.001$} \\
\hline & $>3.5$ & 65.4 & 61.5 & 41.0 & $71.11(61.86-80.36)$ & $90.00(20.40-159.60)$ & \\
\hline \multirow{2}{*}{ Age } & $\leq 60$ & 53.1 & 44.7 & 29.8 & $57.82(49.24-66.40)$ & $38.00(18.69-57.32)$ & \multirow{2}{*}{0.050} \\
\hline & $>60$ & 44.1 & 37.5 & - & $49.93(43.58-56.29)$ & $29.00(20.27-37.73)$ & \\
\hline
\end{tabular}

Table II: Mann-Whitney U-test and Kruskal-Wallis H-test analysis results.

\begin{tabular}{|c|c|c|c|c|}
\hline \multirow{2}{*}{\multicolumn{2}{|c|}{ Variables }} & \multicolumn{2}{|r|}{ RDW } & \multirow{2}{*}{ p-value } \\
\hline & & \multirow{2}{*}{$\begin{array}{l}\text { Mean } \pm \text { SD } \\
14.90 \pm 2.62\end{array}$} & \multirow{2}{*}{ 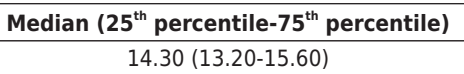 } & \\
\hline \multirow{3}{*}{ Location } & Cardia & & & \multirow{3}{*}{$0.905^{b}$} \\
\hline & Corpus & $15.27 \pm 3.19$ & $14.30(13.30-16.10)$ & \\
\hline & Antrum & $15.16 \pm 2.86$ & $14.35(13.20-16.10)$ & \\
\hline \multirow{4}{*}{ Surgical procedure } & Open Total & $15.35 \pm 2.93$ & $14.60(13.40-16.40)$ & \multirow{4}{*}{$0.001^{b}$} \\
\hline & Open Subtotal & $15.78 \pm 3.54$ & $14.60(13.40-17.45)$ & \\
\hline & Lap. Total & $14.22 \pm 1.35$ & $14.00(13.10-15.10)$ & \\
\hline & Lap. Subtotal & $14.32 \pm 1.87$ & $13.70(13.00-14.83)$ & \\
\hline \multirow{4}{*}{ T Stage } & T1 & $14.81 \pm 3.14$ & $13.85(13.13-14.78)$ & \multirow{4}{*}{$0.038^{b}$} \\
\hline & T2 & $14.55 \pm 1.85$ & $14.20(13.20-15.10)$ & \\
\hline & T3 & $14.96 \pm 2.89$ & $14.25(13.03-15.70)$ & \\
\hline & T4 & $15.48 \pm 2.93$ & $14.60(13.30-16.50)$ & \\
\hline \multirow{2}{*}{$\mathrm{N}$ status } & Negative & $14.61 \pm 2.31$ & $14.00(13.03-15.10)$ & \multirow{2}{*}{$0.006^{\mathrm{a}}$} \\
\hline & Positive & $15.35 \pm 3.01$ & $14.60(13.30-16.20)$ & \\
\hline \multirow{7}{*}{ Stage } & $1 \mathrm{~A}$ & $14.39 \pm 2.42$ & $13.70(13.05-14.60)$ & \multirow{7}{*}{$0.032^{b}$} \\
\hline & 1B & $15.13 \pm 3.22$ & $14.25(13.40-15.48)$ & \\
\hline & $2 \mathrm{~A}$ & $14.70 \pm 2.20$ & $14.00(13.00-16.00)$ & \\
\hline & $2 \mathrm{~B}$ & $15.27 \pm 2.56$ & $14.70(13.30-16.50)$ & \\
\hline & $3 \mathrm{~A}$ & $15.49 \pm 3.40$ & $14.45(13.00-16.48)$ & \\
\hline & $3 B$ & $15.97 \pm 3.53$ & $15.00(13.68-16.68)$ & \\
\hline & $3 \mathrm{C}$ & $14.82 \pm 2.37$ & $14.40(13.13-15.90)$ & \\
\hline \multirow{2}{*}{ Albumin } & $\leq 3.5$ & $16.20 \pm 3.26$ & $15.30(14.05-17.45)$ & \multirow{2}{*}{$<0.001^{\mathrm{a}}$} \\
\hline & $>3.5$ & $14.32 \pm 2.23$ & $13.70(13.00-14.90)$ & \\
\hline \multirow{2}{*}{ Age } & $\leq 60$ & $14.71 \pm 2.68$ & $14.00(13.00-15.45)$ & \multirow{2}{*}{$<0.001^{\mathrm{a}}$} \\
\hline & $>60$ & $15.45 \pm 2.98$ & $14.60(13.60-16.30)$ & \\
\hline \multirow{2}{*}{ Stage } & Early stage & $14.82 \pm 2.56$ & $14.00(13.20-15.35)$ & \multirow{2}{*}{$0.042^{\mathrm{a}}$} \\
\hline & Advanced stage & $15.37 \pm 3.10$ & $14.60(13.20-16.20)$ & \\
\hline
\end{tabular}




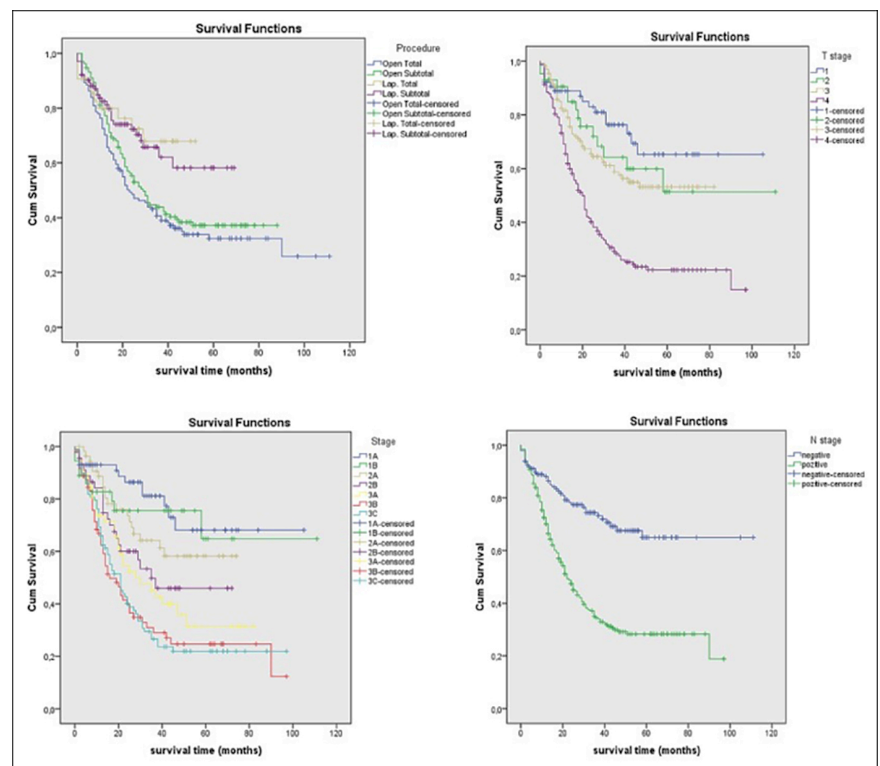

Figure 1: The KaplaN-Meier survival curve, according to procedure, $\mathrm{T}$ stage, stage group, $\mathbf{n}$ stage.
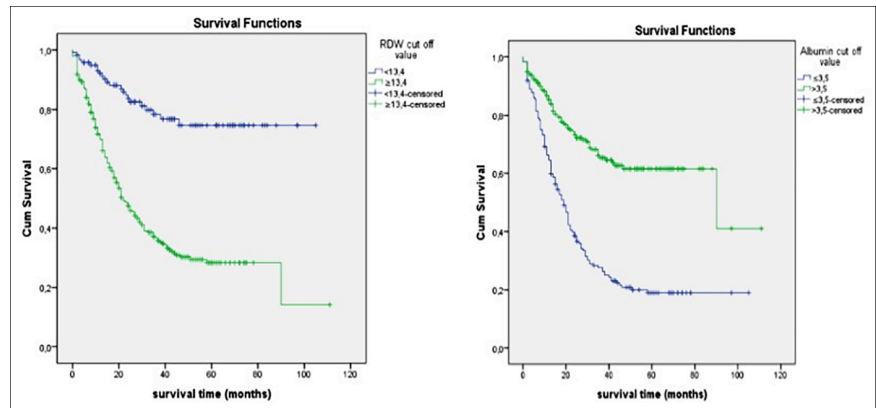

Figure 2: The Kaplan-Meier survival curve according to RDW and Albumin values.

It was statistically shown that RDW increases as T stage increases $(p=0.038)$. Likewise, RDW in node negative patients was shown to be statistically lower $(p=0.006)$. As a result, the relation of RDW increase with advanced stage was found to be statistically significant $(p=0.032)$.

RDW value in patients with hypoalbuminemia was statistically significantly high $(p<0.001)$. According to the age group, RDW value was significantly lower in the 60 years and under groups ( $p<0.001$ ). RDW value was found to increase with the number of metastatic lymph nodes increases $(r=0.101 p=$ 0.040, Table II).

\section{DISCUSSION}

The issue that draws attention in recent years related to cancer is the cause and result of chronic inflammation, and the relationship between cancer and inflammation has been examined. The relationship between cancer and inflammation may be related to malnutrition, immune disorder, angiogenesis, platelet and cytokine activation. The carcinogenesis has been explained by the inflammatory response and was first introduced by Virchow in many articles. ${ }^{9}$ Studies show that tumor-related inflammation and tumor-induced microenviron-- ment plays a more important role in the progression of cancer, metastasis and clinical prognosis. ${ }^{10}$ Inflammation plays an important role in tumor pathogenesis. In addition, hepatitis is associated with many inflammatory diseases along with pancreatitis. ${ }^{11}$ RDW has gained increasing attention in recent years, for many malignancies. Especially, high RDW value has been reported to be associated with survival in many types of cancer (lung, gastric, esophagus, hepatocelIular, colorectal, breast). ${ }^{12-15}$ RDW shows the variability of red blood cells (erythrocytes) and has been used in diagnosis and differential diagnosis in anemia, infectious, cardiovascular diseases, trauma and many types of cancer. ${ }^{16}$ The high RDW in cancer may be due to inflammation caused by cancer cells, inhibition against erythropoietin, reduced iron release from macrophages, shortening the life of the red blood cell, inactive red cell production and the tumoral microenvironment. ${ }^{17,18}$ Apart from inflammation, oxidative stress has also been shown to disrupt DNA repair and increase RDW. However, it is still unclear whether RDW is still linked to cancer-induced inflammation, tumor size, volume, or other factors. RDW is not affected by gender, age, and hemoglobin level. There was no statistical relationship between gender and RDW ( $p=0.064)$, and it was found to be borderline significant with age in the present study $(p=0.05)$. According to these results, when eliminating other factors affecting RDW, the accuracy of the results of the study increases even more. Being an easily accessible and inexpensive method also increases its applicability.

This study showed that preoperative high RDW value is associated with poor survival; and patients with high RDW values should be paid more attention $(p<0.001)$. In addition to these findings, RDW value was high in patients with advanced $T$ stage, node-positive status, advanced TNM stage, hypoalbuminemia, over 60 years old, and more metastatic lymph nodes. These showed that RDW elevation can be used as an indicator of malignant progression in gastric cancer and to predict the survival rates of patients with gastric cancer.

There are studies in the literature that support the present study and show that RDW value is a poor prognostic factor. ${ }^{12}$ The results similar to this study have been obtained in recent studies. Hirahara et al. and Pan et al. showed that preoperative RDW value is a poor prognostic factor in gastric cancer patients. ${ }^{19,20}$ Preoperative RDW value can help in differentiating between gastric cancers and intestinal metaplasia. ${ }^{21}$ Shota et al. showed that postoperative RDW value is associated with survival. ${ }^{22}$ The postoperative RDW value was not evaluated in this study. With new studies, correct predictions can be made about the prognosis by looking at the postoperative RDW value and other markers.

The RDW value can be used safely in predicting the prognosis because it is cheap, fast and easily accessible. At the same time, RDW elevation may also cause cardiovascular disease due to inflammation, atherosclerosis and coagulation. This should keep alert for postoperative complications. ${ }^{23}$ 
It is known that preoperative nutritional status has an important effect on the prognosis of the disease in gastric cancer. It was revealed that preoperative albumin values were closely related to prognosis in esophagogastric junction tumors in a study conducted by Han et al. ${ }^{24}$ It was again shown that preoperative nutritional status was associated with survival in patients with gastric cancer in another study and preoperative nutritional support should be given to the patients who are required. ${ }^{25}$ It was statistically revealed that low preoperative albumin is a poor prognostic factor in patients with gastric cancer in this study $(p<0.001)$. Since RDW is known to be related to nutritional status, poor prognostic relationship with RDW in present study may be due to this situation.

The fact that factors such as sample size, exclusion of reasons that may increase the RDW value, age and gender do not have a significant relationship with the RDW value increase the strength of this study.

There are some limitations regarding to the study. It is primarily a retrospective cohort and single-center study. Secondly, only the preoperative RDW value was used and postoperative RDW value could be included in the study. However, the RDW cut-off value was selected as $13.4 \%$ for some previous studies, and there is no standardization for all studies.

\section{CONCLUSION}

This study shows the prognostic value of preoperative RDW level in patients with non-metastatic gastric cancer and it has been proven that high RDW value is a poor prognostic factor in gastric cancer. Thus, RDW will assist us in making clinical decisions regarding gastric cancer outcomes. The fact that RDW is cheap, fast and easily accessible will also provide convenience to the clinician. RDW value should be supported by other markers in predicting prognosis and new studies should focus on long-term results.

\section{ETHICAL APPROVAL:}

This study was approved by the Ethical Committee of Ankara University School of Medicine.

\section{PATIENTS' CONSENT:}

Because this study was retrospective, the patients' consents were waived.

\section{CONFLICT OF INTEREST:}

All authors declared no conflict of interest.

\section{AUTHORS' CONTRIBUTION:}

CY: Data curation, writing original draft preparation, writing reviewing and editing.

OE: Data collecting, quality control of data and algorithms, writing original draft preparation.

SÇ: Conceptualisation, methodology, software, writingreviewing and editing.
BB: Statistical analysis, data collecting.

AEÜ, SD: Visualisation, investigation, validation, supervision.

\section{REFERENCES}

1. Ferlay J, Shin HR, Bray F, Forman D, Mathers C, Parkin DM. Estimates of worldwide burden of cancer in 2008: GLOBOCAN 2008. Int J Cancer 2010; 127(12):2893-917. doi: 10.1002/ijc. 25516.

2. Montagnana M, Danese E. Red cell distribution width and cancer. Annals Transl Med 2016; 4(20):399. doi: 10.21037/atm.2016.10.50.

3. Evans TC, Jehle D. The red blood cell distribution width. J Emergency Med 1991; 9:71-4.

4. Li N, Zhou H, Tang Q. Red blood cell distribution width: A novel predictive indicator for cardiovascular and cerebrovascular diseases. Dis Markers 2017; 2017:7089493. doi: 10.1155/2017/7089493.

5. Ichinose J, Murakawa T, Kawashima M, Nagayama K, Nitadori Jl, Anraku M, et al. Prognostic significance of red cell distribution width in elderly patients undergoing resection for non-small cell lung cancer. J Thorac Dis 2016; 8(12):3658. doi: 10.21037/jtd.2016.12.44.

6. Kim SH, Yeon JH, Park KN, Oh SH, Choi SP, Kim YM, et al. The association of Red cell distribution width and in-hospital mortality in older adults admitted to the emergency department. Scand J Trauma Resusc Emerg Med 2016; 24(1):81. doi: 10.1186/s13049-016-0274-8.

7. Hu L, Li M, Ding Y, Pu L, Liu J, Xie J, et al. Prognostic value of RDW in cancers: a systematic review and meta-analysis. Oncotarget 2017; 8(9):16027. doi: 10.18632/oncotarget. 13784.

8. Pietrzyk L, Plewa ZDB, Wang ZQ. Prognostic role of the lymphocyte-to-monocyte ratio in patients undergoing resection for nonmetastatic rectal cancer. Medicine 2016; 95(44):e4945. doi: 10.1097/MD.0000000000004945.

9. Wu QB, Wang M, Hu T, He WB, Wang ZQ. Prognostic role of the lymphocyte-to-monocyte ratio in patients undergoing resection for nonmetastatic rectal cancer. Medicine 2016; 95(44). doi: 10.1097/MD.0000000000004945.

10. Gao L, Zhang $H$, Zhang B, Zhang L, Wang C. Prognostic value of combination of preoperative platelet count and mean platelet volume in patients with resectable non-small cell lung cancer. Oncotarget 2017; 8(9):15632. doi: 10.18632/oncotarget. 14921.

11. Fu Y, Mao Y, Chen S, Yang A, Zhang Q. A novel inflammation-and Nutrition-Based Prognostic System for patients with laryngeal squamous cell carcinoma: Combination of Red Blood cell distribution width and body Mass Index (COR-BMI). PLoS One 2016 11(9). doi: 10.1371/journal.pone.0163282.

12. Yazici P, Demir U, Bozkurt E, Isil GR, Mihmanli M. The role of red cell distribution width in the prognosis of patients with gastric cancer. Cancer Biomark 2017; 18(1):19-25. doi: 10.3233/CBM-160668.

13. Chen GP, Huang $Y$, Yang $X$, Feng JF. A nomogram to predict prognostic value of red cell distribution width in patients with esophageal cancer. Mediators Inflamm 2015; 2015:854670. doi: $10.1155 / 2015 / 854670$.

14. Goyal H, Hu ZD. Prognostic value of red blood cell distribution 
width in hepatocellular carcinoma. Annals Transl Medicine 2017; 5(13):271. doi: 10.21037/atm.2017.06.30.

15. Zhang X, Wu Q, Hu T, Gu C, Bi L, Wang Z. Elevated red blood cell distribution width contributes to poor prognosis in patients undergoing resection for nonmetastatic rectal cancer. Medicine 2018; 97(3):e9641. doi: 10.1097/MD. 0000000000009641.

16. Sargento L, Simões AV, Longo S, Lousada N, Palma dos Reis R. Red blood cell distribution width is a survival predictor beyond anemia and Nt-ProBNP in stable optimally medicated heart failure with reduced ejection fraction outpatients. Clin Hemorheol Microcirc 2017; 65(2):185-94. doi: 10.3233/CH16155.

17. Pagès $F$, Berger $A$, Camus $M$, Sanchez-Cabo $F$, Costes $A$, Molidor R, et al. Effector memory $T$ cells, early metastasis, and survival in colorectal cancer. N Engl J Med 2005; 353(25):2654-66. doi: 10.1056/NEJMoa051424.

18. Grivennikov SI, Greten FR, Karin M. Immunity, inflammation, and cancer. Cell 2010; 140(6):883-99.

19. Hirahara N, Tajima Y, Fujii Y, Kaji S, Yamamoto T, Hyakudomi $\mathrm{R}$, et al. Comprehensive analysis of red blood cell distribution width as a preoperative prognostic predictor in gastric cancer. Anticancer Res 2019; 39(6):3121-30. doi: 10.21873/ anticanres.13448.

20. Pan J, Borné $Y$, Engström G. The relationship between red cell distribution width and all-cause and cause-specific mortality in a general population. Sci Rep 2019; 9(1):16208. doi: 10.1038/s41598-019-52708-2.

21. Aksoy EK, Kantarcı S, Torgutalp M, Akpınar MY, Sapmaz FP, Yalçın GŞ, et al. The importance of complete blood count parameters in the screening of gastric cancer. Przeglad gastroenterologiczny 2019; 14(3):183-7. doi: 10.5114/pg. 2019.88167.

22. Shota S, Saito H, Kono Y, Murakami Y, Shishido Y, Miyatani K, et al. Prognostic significance of pre-and post-operative red-cell distribution width in patients with gastric cancer. J Gastrointest Surg 2020; 24(5):1010-17. doi: 10.1007/ s11605-019-04392-w.

23. Lippi G, Targher G, Montagnana M, Salvagno GL, Zoppini G, Guidi GC. Relation between red blood cell distribution width and inflammatory biomarkers in a large cohort of unselected outpatients. Arch Pathol Lab Med 2009; 133(4):628-32. doi: 10.1043/1543-2165-133.4.628.

24. Han WX, Chen ZM, Wei ZJ, Xu AM. Preoperative pre-albumin predicts prognosis of patients after gastrectomy for adenocarcinoma of esophagogastric junction. World J Surg Oncol 2016; 14(1):279. doi: 10.1186/s12957-016-1035-x.

25. Nozoe T, Ninomiya M, Maeda T, Matsukuma A, Nakashima $H$, Ezaki T. Prognostic nutritional index: A tool to predict the biological aggressiveness of gastric carcinoma. Surg Today 2010; 40(5):440-3. 